\title{
OS EFEITOS DE DIFERENTES REGIMES DE IRRIGAÇÃO SOBRE VÁRIOS CARACTERES DA CULTURA DA CEBOLA (Allium cepa, L.) *
}

\author{
A. E. KLAR ** \\ T. KIMOTO \\ S. SIMÃo $* * *$
}

\section{RESUMO}

\begin{abstract}
Os estudos relativos as melhores condições de umidade do solo para a cultura da cebola são importantes, para a região em que os ensaios foram instalados, devido a necessidade de aplicação da água suplementar.

O experimento foi conduzido utilizando-se do processo de bulbinhos para a propagação da cultura, do método de sulcos de infiltração para a irrigação e do método gravimétrico direto para a avaliação da umidade do solo. Implantaram-se, os ensaios, num solo Latosol Vermelho Escuro-Orto (COMISSAO DE SOLOS, 1960)! Os tratamentos diferenciaram-se pelos potenciais matriciais médios mínimos de água permitidos ao solo antes de cada irrigação em: $-0,5 ;-1,0 ;-6,0$ e $-15,0$ barias. Verificouse, ainda, a evapotranspiração potencial, que se conduziu com valores intermediários.
\end{abstract}

\section{INTRODUÇÃO}

Os efeitos gerais de carência ou excesso de umidade do solo, no crescimento das plantas, são bastantes conhecidos. Existe, portanto, um intervalo no teor de umidade do solo, que proporciona melhores condições de disponibilidade de água às plantas visando o crescimento e produção. Este assunto foi estudado por diversos autores, entre os quais HAGAN (1955), DENMEAD e SHAW (1962), EAGLEMAN e DECKER (1965) e GARDNER (1960) que verificaram as condições de interferência de fatores de solo, de clima e da própria planta, interagindo nos diversos caracteres dos vegetais.

A cultura da cebola sob influência da umidade do solo, foi estudada por CURRY (1937 a 1941), MAC GILLIVRAY e DONEEN

\footnotetext{
* Entregue para publicação em 29/12/1972.

** Departamento de Fitotecnia da Fac. de Ciências Médicas e Biológicas de Botucatu (SP).

*** Departamento de Agricultura e Horticultura da E.S.A. "Luiz de Queiroz" - Piracicaba (SP).
} 
(1947), DRINKWATER e JANES (1955) e SING e ALDERFER (1966), além de outros autores, que verificaram maiores rendimentos em altos potenciais de água no solo.

Os objetivos do presente estudo prendem-se às condições mais favoráveis de umidade do solo à cultura da cebola - Allium cepa, L. - no que concerne ao desenvolvimento do bulbo e da parte aérea complementando os trabalhos KLAR et al, 1971.

\section{MATERIAIS E MÉTODOS}

Os dados meteorológicos, necessários ao desenvolvimento destes estudos, foram obtidos do Pôsto Meteorológico da ESALQ-USP, situado à $500 \mathrm{~m}$ do experimento. Utilizou-se do processo de Penman - Bavel (BAVEL, 1956) para a estimativa da evapotranspiração potencial durante o ciclo da cultura.

Escolheu-se uma linhagem da variedade Baia Periforme Precoce, propagada através do processo de bulbinhos (DIAS, 1963, 1966).

A irrigação foi conduzida pelo método de sulcos de infiltração e as variações de umidade do solo foram estimadas, diariamente, às profundidades de $0-20 ; 20-40$ e $40-60 \mathrm{~cm}$ pelo método gravimétrico padrão.

O experimento foi instalado num solo Latosol Vermelho Escuro - Orto (COMISSÃO DE SOLOS, 1960) classificado ao nível de série por RANZANI, et al (1966) como Série "Luiz de Queiroz".

Os ensaios foram delineados em blocos ao acaso com cinco repetições, com os tratamentos distinguindo-se quanto aos potenciais matriciais mínimos de umidade do solo permitidos: $-0,5$; $-1,0 ;-6,0$ e $-15,0$ barias, respectivamente, denominados A, B, C e D. Estes valores foram extraídos da curva de potencial - umidade do solo (Fig. 1) determinada na membrana e placa de Richards. (RICHARDS, 1947).

Configurou-se um espaçamento de $50 \mathrm{~cm}$ entre linhas e $10 \mathrm{~cm}$ entre plantas, com cada parcela perfazendo duas linhas de 20 metros, recebendo irrigação de ambos os lados.

Os dados biométricos relatados foram determinados com as médias de 5 plantas, tomadas ao acaso. Utilizou-se de valores de 1 a 5, transformados em porcentagem para a avaliação da incidência de Alternaria porri, Ellis em todas as plantas das parcelas. A precocidade foi avaliada através da porcentagem das duas primeiras colheitas, de quatro ocorridas. Todos os valores dados em porcentagem foram transformados em arc/sen $\sqrt{\%}$ para efeito de análise estatística. 


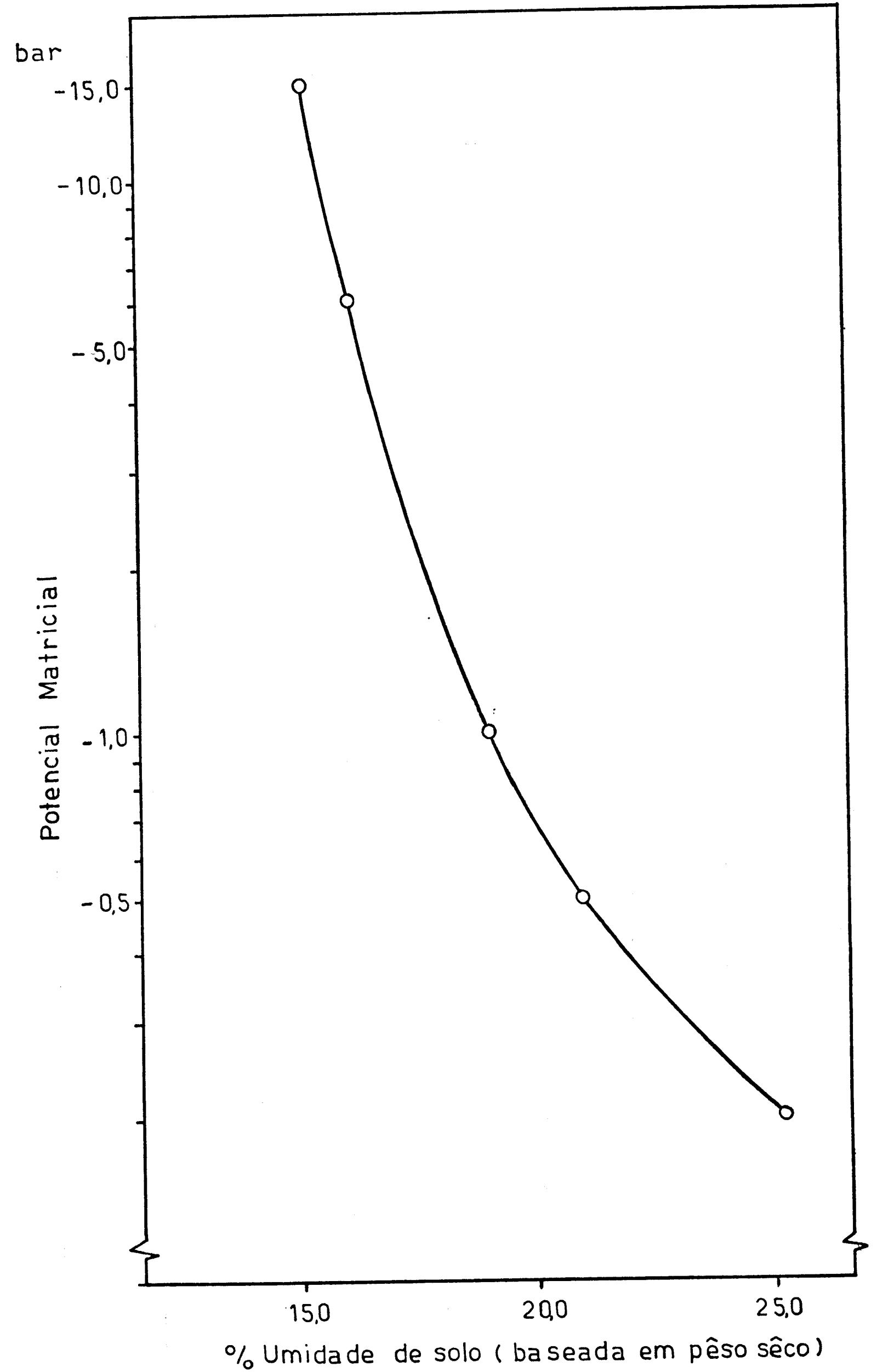

Fig. 1 - Curva característica de potencial - umidade do solo. 


\section{RESULTADOS}

Os ensaios foram realizados nos anos agrícolas de 1966 e 1967.

\subsection{Ensaio de 1966}

O ensaio instalado a 14 de março de 1966 apresentou os resultados que constam dos QUADROS 1 e 2, e das Figs. 2 e 3.

QUADRO 1. - Valôres resultantes das características estudadas no ano de 1966.

\begin{tabular}{|c|c|c|c|c|c|c|c|c|}
\hline \multirow{2}{*}{$\begin{array}{c}\text { Características } \\
\text { estudadas }\end{array}$} & \multicolumn{2}{|c|}{ Média dos } & \multicolumn{2}{|c|}{ tratamentos } & \multirow{2}{*}{$\begin{array}{c}\text { Teste } \\
\text { F }\end{array}$} & \multicolumn{2}{|c|}{ d.m.s. (Tukey) } & \multirow{2}{*}{ C.V. \% } \\
\hline & A & B & $\mathbf{C}$ & D & & $5 \%$ & $1 \%$ & \\
\hline Peso do bulbo(g) & 173,97 & 135,43 & 118,86 & 120,86 & $18,70 * *$ & 26,07 & 35,16 & 8,60 \\
\hline $\begin{array}{l}\text { Diâmetro do bulbo } \\
(\mathrm{cm})\end{array}$ & 6,99 & 6,36 & 5,94 & 5,95 & $9,13 * *$ & 0,84 & 1,13 & 6,03 \\
\hline $\begin{array}{l}\text { Diâmetro do talo } \\
(\mathrm{cm})\end{array}$ & 63,51 & 1,56 & 1,49 & 1,43 & $8,76 * *$ & 0,27 & 0,37 & 8,86 \\
\hline Peso das folhas $(\mathrm{g})$ & 1,86 & 43,53 & 37,24 & 33,59 & $6,72^{* *}$ & 22,87 & 30,87 & 23,11 \\
\hline $\begin{array}{l}\text { Comprimento da } \\
\text { maior folha (g) }\end{array}$ & 62,51 & 56,36 & 53,38 & 50,80 & $8,87 * *$ & 7,43 & 10,07 & 6,06 \\
\hline Número de folhas & 12,47 & 10,93 & 10,98 & 10,41 & 2,68 & - & - & 10,04 \\
\hline $\begin{array}{l}\text { Incidência de } \\
\text { Alternaria porri, } \\
\text { Ellis }(\%)\end{array}$ & 41,39 & 39,49 & 30,00 & 33,89 & 2,45 & - & - & 11,22 \\
\hline Precocidade $(\%)$ & $L Z^{\prime} 6 L$ & 79,74 & 82,14 & 75,80 & 0,57 & - & - & 8,08 \\
\hline
\end{tabular}

(**) - Estatisticamente significativo ao nível de $1 \%$ de probabilidade. 
QUADRO 2: Valores da evapotranspiração potencial (Ep), média e precipitação mensal durante o ano de 1966

\begin{tabular}{|c|c|c|c|c|}
\hline 1966 & março & abril & maio & junho \\
\hline $\begin{array}{l}\text { Ep diária (média } \\
\text { em } \mathrm{mm} \text { ) }\end{array}$ & 2,60 & 2,45 & 1,67 & 1,69 \\
\hline $\begin{array}{c}\text { precipitação } \\
(\mathrm{mm})\end{array}$ & 55,6 & 18,2 & 43,7 & - \\
\hline
\end{tabular}

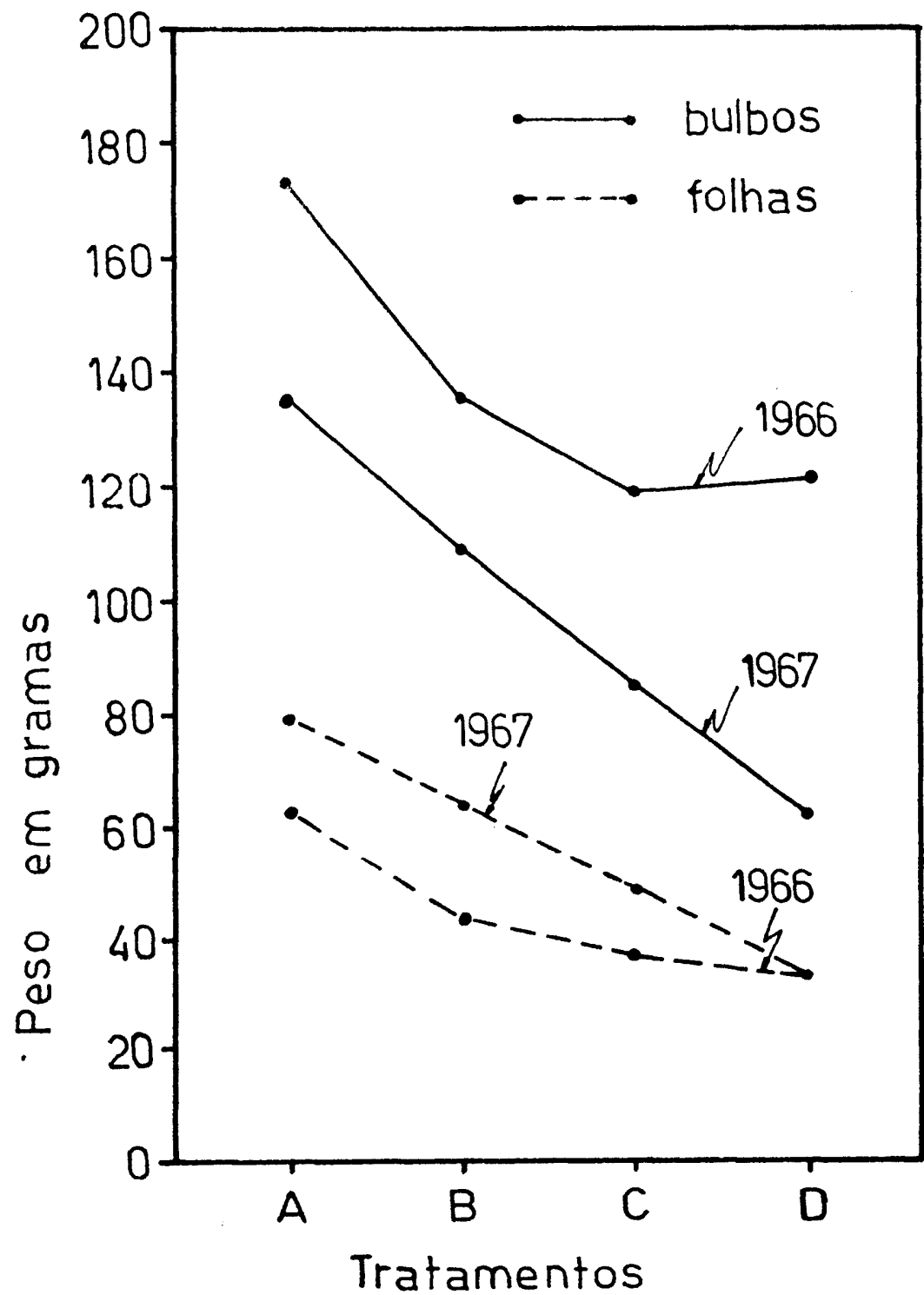

Fig. 2 - Gráficos representativos dos resultados relacionados aos pesos médios de bulbos e folhas. 


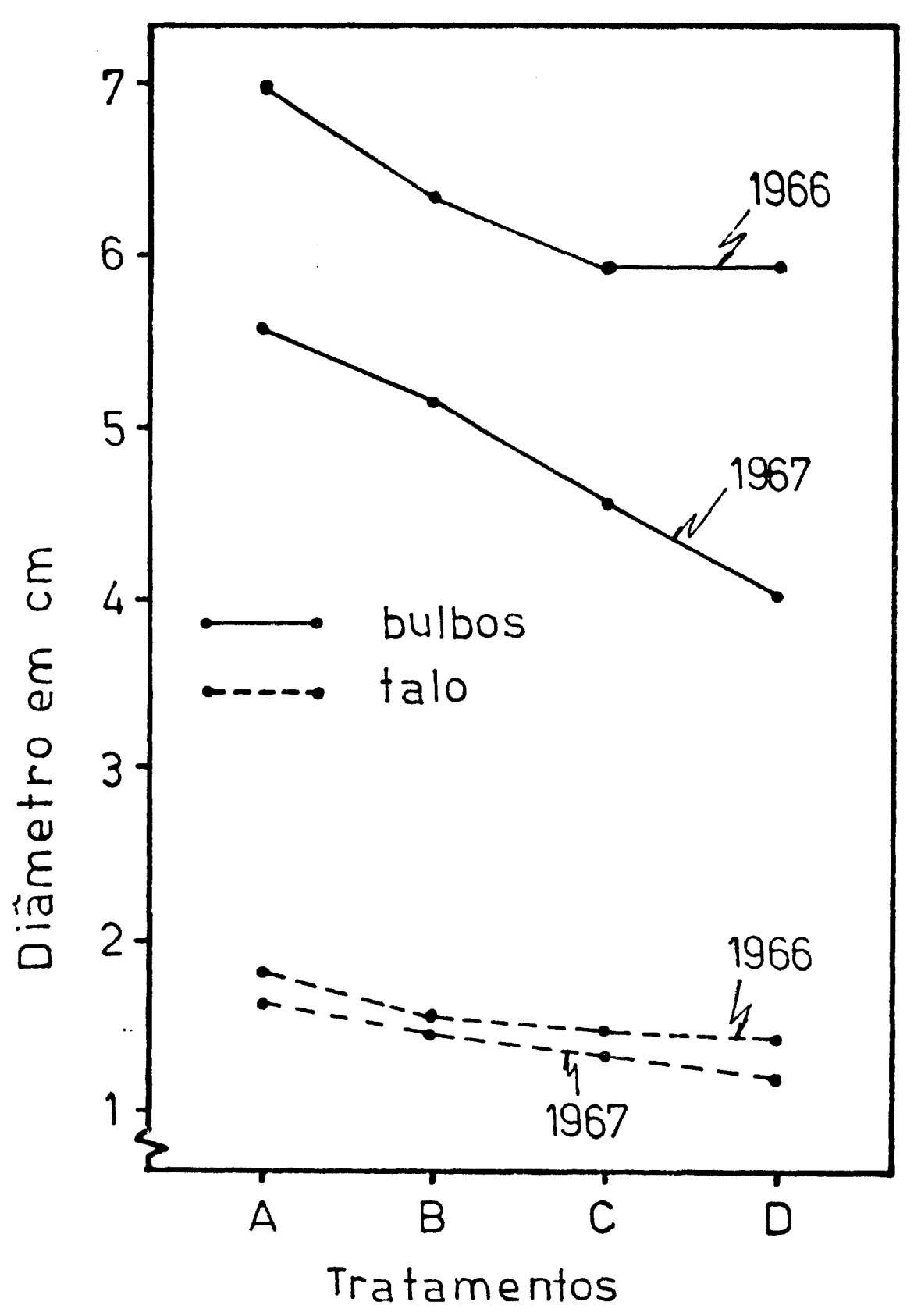

Fig. 3 - Gráficos representativos dos resultados relacionados aos diâmetros do bulbo e do talo.

\subsection{Ensaio de 1967}

Este ensaio foi implantado a 4 ed abril de 1967, sendo os resultados auferidos inclusos nos QUADROS 3 e 4 e das Figs. 4 e 5. 
QUADRO 3. - Valores resultantes das características estudadas no ano de 1967

\begin{tabular}{|c|c|c|c|c|c|c|c|c|}
\hline \multirow{2}{*}{$\begin{array}{c}\text { Características } \\
\text { estudadas }\end{array}$} & \multicolumn{2}{|c|}{ Médias dos } & \multicolumn{2}{|c|}{ tratamentos } & \multirow{2}{*}{$\begin{array}{c}\text { Teste } \\
\text { F }\end{array}$} & \multicolumn{2}{|c|}{$\begin{array}{l}\text { (Tukey) } \\
\text { d.m.s. }\end{array}$} & \multirow{2}{*}{$\begin{array}{r}\text { C.V. } \\
\%\end{array}$} \\
\hline & $\mathbf{A}$ & $\mathbf{B}$ & $\mathbf{C}$ & $\mathbf{D}$ & & $5 \%$ & $1 \%$ & \\
\hline Peso do bulbo(g) & 135,68 & 108,65 & 85,02 & 61,97 & $29,84 * *$ & 26,11 & 33,81 & 5,92 \\
\hline $\begin{array}{l}\text { Diâmetro do bulbo } \\
(\mathrm{cm})\end{array}$ & 5,56 & 5,17 & 4,56 & 4,01 & $17,76 * *$ & 0,73 & 0,94 & 7,49 \\
\hline $\begin{array}{l}\text { Diâmetro do talo } \\
(\mathrm{cm})\end{array}$ & 1,68 & 1,45 & 1,34 & 1,17 & $28,52 * *$ & 0,18 & 0,23 & 6,30 \\
\hline Peso das folhas $(\mathrm{g})$ & 79,19 & 64,20 & 48,62 & 33,35 & $6,23 * *$ & 35,02 & 45,35 & 30,97 \\
\hline $\begin{array}{l}\text { Comprimento da } \\
\text { maior folha }(\mathrm{cm})\end{array}$ & 54,96 & 51,05 & 46,89 & 44,10 & $26,50 * *$ & 4,17 & 5,39 & 4,19 \\
\hline - Número de folhas & 9,89 & 9,72 & 9,82 & 10,39 & 0,14 & 一 & 一 & 1663 \\
\hline $\begin{array}{l}\text { Incidência de } \\
\text { Alternaria porri, } \\
\text { Allis \% }\end{array}$ & 11,01 & 11,02 & 10,92 & 11,72 & 0,068 & 一 & - & 21,22 \\
\hline Precocidade $\%$ & 54,62 & 51,79 & 54,23 & 56,68 & 1,48 & 一 & - & 4,55 \\
\hline
\end{tabular}

QUADRO 4. - Valores da evapotranspiração potencial (Ep) média e precipitação mensal durante o ensaio de 1967

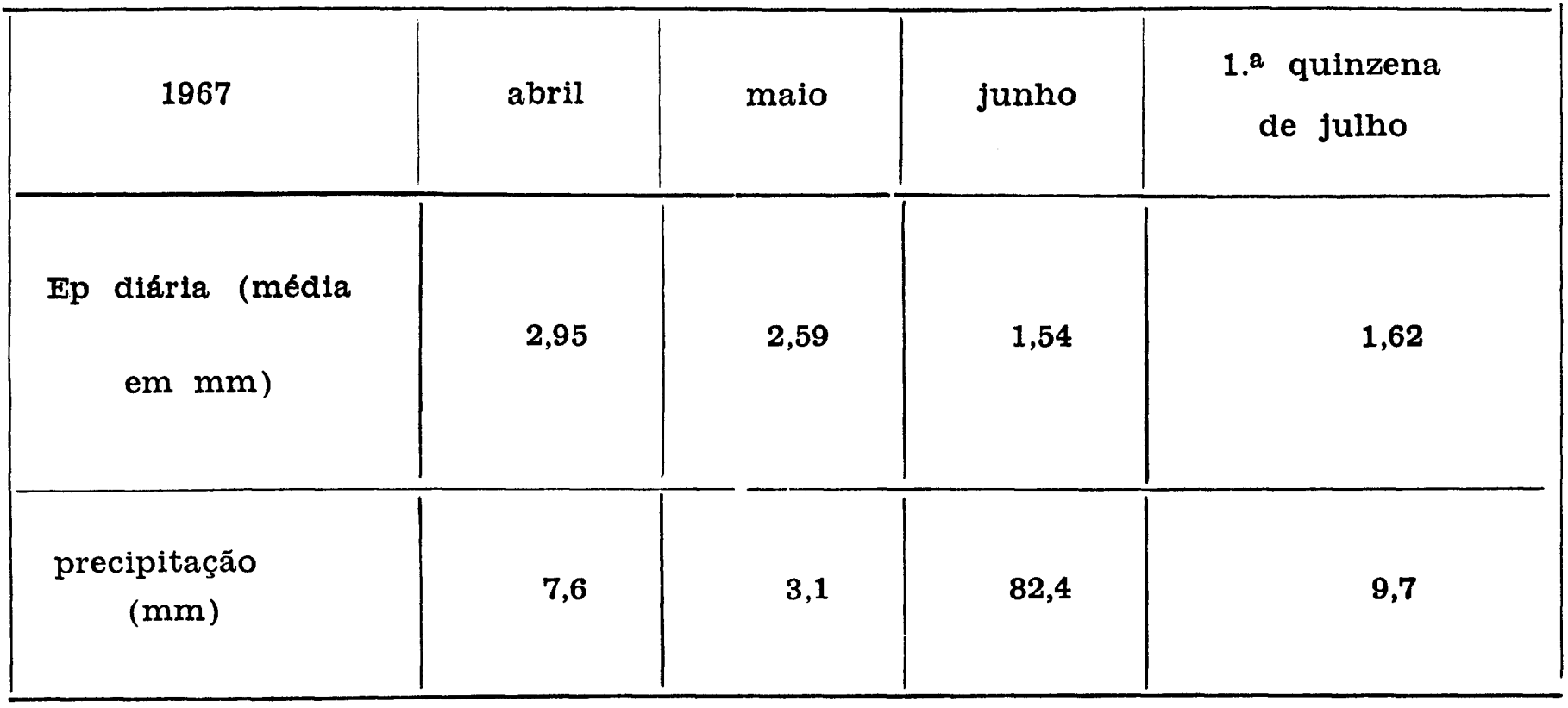




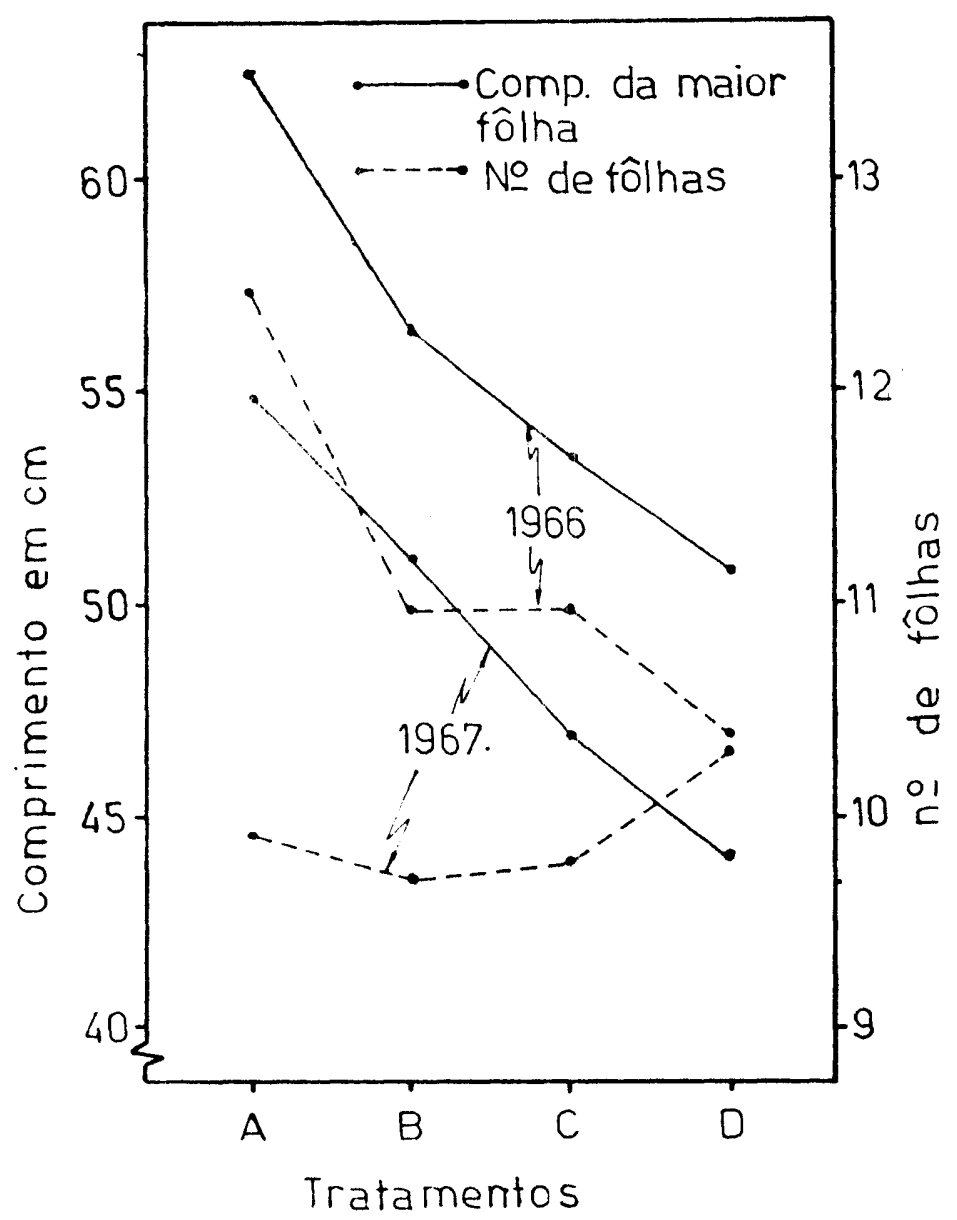

Fig. 4 - Gráficos representativos do comprimento da maior folha e do número de folhas.

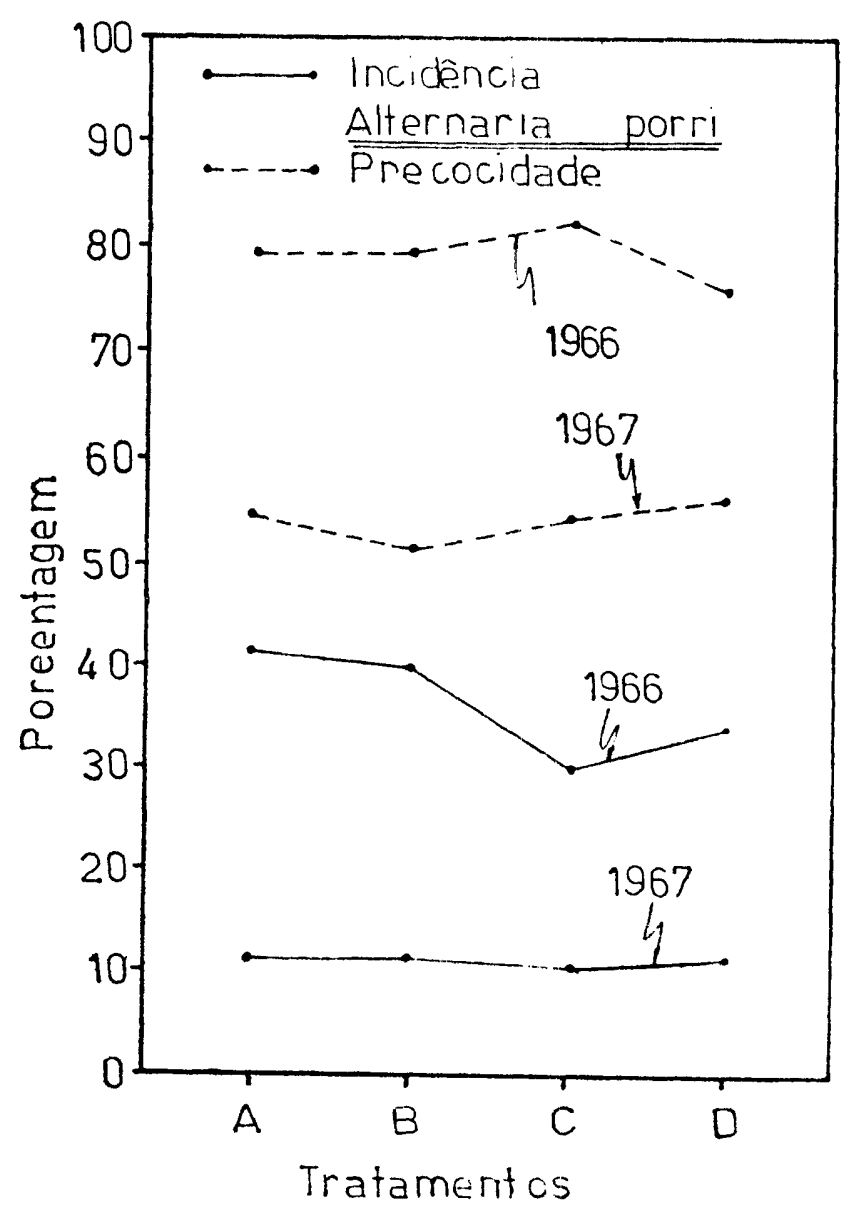

Fig. 5 - Gráficos representativos das porcentagens de incidência de Alternaria e da precocidade. 


\section{DISCUSSÃo}

O período do ano em que a cultura da cebola se desenvolve no Estado de São Paulo não apresenta condições de precipitação suficientes para o desenvolvimento dessas plantas, exigindo a aplicação de água suplementar. Os QUADROS 2 e 4 mostram valores relativos a evapotranspiração potencial e as precipitações ocorridas durante os períodos de experimentação, que aproximam-se bastante, das condições médias anuais do período.

As taxas de evapotranspiração potencial prevalecentes durante os ensaios permitem enquadrá-las como intermediárias na classificação de DENMEAD e SHAW (1962), devido à semelhança dos resultados auferidos no presente trabalho. Aqueles autores encontraram que as plantas murcham a diferentes potenciais de umidade do solo, dependendo da demanda evaporativa da atmosfera.

Outros autores preconizaram a influência das condições atmosféricas no potencial de água nas plantas, como, HAGAN (1955) e BAHRANI e TAYLOR (1961). EAGLEMAN e DECKER (1965) estudando o mesmo assunto verificaram que a evapotranspiração não atingia o valor zero sempre que baixos teores de umidade do solo foram atingidos e que é influenciada pela quantidade de água da porção de solo explorada pelas plantas em adição aos fatores meteorológicos.

Os valores relativos à produção (QUADROS 1 e 2 e Figs. 2 e 3) configuraram a assertiva de que altos teores de umidade do solo predispõem a um melhor desenvolvimento da cultura, confirmando os trabalhos de CURRY (1937 e 1941) e DRINKWATER e JONES (1955).

O peso das folhas, o comprimento da maior folha e o diâmetro do talo (QUADROS 1 e 2 e Figs. 3 e 4), aqui utilizados como parâmetros estimativos do desenvolvimento vegetativo, sofreram significativa influência dos tratamentos configurados com resultados semelhantes aos de produção, ocorrendo de conformidade com os conseguidos por SINGH e ALDERFER (1966) que generalizraam: baixos teores de umidade do solo concorrem intensamente para $o$ decréscimo do desenvolvimento das plantas de cebola.

Ao serem analisados os valores de produção e desenvolvimento vegetativo, configuram-se menores valores para o ano de $1967 \mathrm{em}$ relação ao ano anterior. Justifica-se este fenômeno, pois a produção decresce com o plantio retardado além da época indicada, conforme verificado por SIMÃO (1961).

Os dados que sofreram interferência, estatisticamente, signifi- 
cativa, dos tratamentos, foram um pouco mais consistentes no ano de 1967 e, este fato, provavelmente deve-se à interferência das chuvas ocorridas, não permitindo a total manutenção da variação planejada dos teores de umidade do solo nos tratamentos do ensaio de 1966. (QUADROS 2 e 4). No ano seguinte verifica-se que, apenas no mês de junho ocorreram precipitações consistentes, assim mesmo não bem distribuidas.

Os resultados relativos ao número de folhas não foram afetados pelos tratamentos, provavelmente, por serem um caráter da planta não afetado pelas condições ambientais.

Embora não houvesse variação significativa entre os tratamentos no que concerne a incidência de doenças, (QUADROS 1 e 3, Fig. 5) convém salientar, que a ocorrência de "Alternaria" foi mais intensa no ano de 1966. Explica-se, provavelmente pela distribuição das precipitações (QUADROS 2 e 4). Estes resultados aproximam-se bastante daqueles obtidos por CURRY (1937).

A maturação das plantas, também, não sofreu a intervenção das diferentes variações nos teores de umidade do solo (QUADROS 1 e 3 e Fig. 5) sob as condições climáticas e de solo ocorridas. CURRY (1937) encontrou resultados semelhantes. Entretanto DRINKWATER e JANES (1955) verificaram variações significativas.

A análise estatística conjunta dos caracteres comuns, estudados em ambos os ensaios demonstrou não haver, em qualquer deles, interação, tratamentos por anos.

\section{CONCLUSÕES}

Os resultados auferidos sob condições de solo, clima, variedade específica e métodos utilizados, conduziram às seguintes conclusões :

a - as variedades relacionadas ao peso do bulbo, diâmetro do bulbo e do talo, peso das folhas e comprimento das folhas, responderam favoravelmente aos potenciais mais elevados de umidade do solo (maiores que $-0,5$ bar);

b) - as características relativas à precocidade, número de folhas e incidência de Atlernária porri, ELLIS, não mostraram variações significativas, sob os tratamentos utilizados. 


\section{SUMMARY}

\section{SOME CARACTERISTICS OF ONIUM CROP AS AFFECTED BY IRRIGATION SYSTEMS}

Studies on soil moisture conditions for onion crop are important to state of São Paulo, primarily because in the regions where onion is cultivated, supplementar water is necessary.

The experiment was conducted by using onion sets propagation, furrow irrigation method, and the standard gravimetric method for soil moisture content determination the treatments were differentiated by the allowed minimal water potential before each irrigation, as follow: $-0,5 ;-1,0 ;-6,0$ and $-15,0$ bars.

The following conclusions were obtained under the climatic conditions observed during the experiment, soil, variety and methods used.

a) positive responses to high soil moisture potentials ( $-0,5$ bar) were observed in the data related to bulb weight, bulb and stalk diameter, leaf weight;

b) maturity, number of leaves and incidence of Alternaria porri, Ellis, were not significantly by the treatments used.

\section{LITERATURA CITADA}

BAHRANI, B. and S. A. TAYLOR, 1961 - Influence of soil moisture potential and evaporative demand on the atual. evapotranspiration from an alfalfa field. Agron. J. 53:233-236. 1961.

BAVEL, C. H. M. VAN, 1956 - A nomogram to estimate maximum evapotranspiration. N. Carol. State Col.

COMISSAO DE SOLOS do C.N.E.D.A., 1960 - Levantamento de reconhecimento dos solos do Est. de S. Paulo. Rio de Janeiro, Centro Nacional de Ensino e Pesquisas Agronômicas. $634 \mathrm{p}$.

CURRY, A. S., 1937 - Irrigation experiments with the early grano onion. Bull. New Mex. agric. Exp. Stn. 245, 39 p., 1941 - Effect of irrigation practices on the growth and yield of white grano onions. Bull. New Mex. agric. Exp. Stn. 281, 34 p.

DENMEAD, O. T. \& R. H. SHAW, 1962 - Availability of soil water to plants as affected by moisture content and meteorological conditions. Agron. J. $54(5): 385-390$.

DRINKWATER W. O. \& B. E. JAMES, 1955 - Effects of irrigation and soil moisture on maturity, yield and storage of two onion by brids. Proc. Am. Soc. hort. Sci. 66:267-278.

EAGLEMAN, J. R. \& W. L. DECKER, 1965 - The role of soil moisture in evaporation. Agron. J. 57(6):626-629. 
GARDNER, W. R., 1960 - Dinamic aspects of water availability to plants. Soil Sci. 89:63-73.

HAGAN, R. M., 1955 - Factors affecting soil moisture-plant growth relations Int. hort. Congr. 14th. Wageningen, Rap.: 82-102.

KLAR, A. E., T. KIMOTO \& S. SIMÃO, 1971 - Estudo das necessidades d'água de uma cultura de cebola (Allium cepa, L.). Ciência e Cultura 23(5): 609-618.

MAC GILLIVRAY, J. H. \& L. D. DONEEN, 1947 - Irrigation studies with truck crops. Calif. Agric. Exp. Stn Truck Crops 40.

RANZANI G., D. FREIRE e T. KINJO, 1966 - Carta de Solos do Município de Piracicaba. Piracicaba, Centro de Estudos de Solos, 85 p.

RICHARDS L. A., 1947 - Pressure - membrane apparatus, construction and use. Agr. Eng. 28:451-454.

SIMÃO S., 1961 - Influência da época e da poda sobre o rendimento da cebola. Olericultura 1:16-22.

SING R. \& R. B. ALDERFER, 1966 - Effects of soil moisture at different periods of growth of some vegetable crops. Soil Sci 1(1):69-80.

SLATYER, R. O., 1967 - Plant water relationship. New York - Acad. Press Ltd. $366 \mathrm{p}$. 